\title{
Exposure to Infliximab During Pregnancy: Post-Marketing Experience
}

\author{
Anja Geldhof ${ }^{1}\left[\right.$ ] Jennifer Slater ${ }^{2} \cdot$ Michael Clark $^{3} \cdot$ Urmila Chandran $^{4} \cdot$ Danielle Coppola $^{4}$
}

Published online: 1 November 2019

(c) The Author(s) 2019

\begin{abstract}
Background Women of childbearing potential are often treated with monoclonal antibodies to control chronic and debilitating inflammatory diseases. Remicade ${ }^{\circledR}$ (innovator infliximab [IFX]) may cross the placenta after the first trimester of pregnancy. Hence, evidence is needed to optimize treatment while carefully weighing benefits and risks to the mother and child. Here, we report on birth and infant outcomes (up to 2 years) following gestational exposure to IFX based on a summary of cumulative pregnancy reports in women exposed to IFX during pregnancy from the Janssen global safety database. Methods Prospective and medically confirmed safety data on IFX-exposed pregnancies from Janssen's global safety surveillance database since authorization in 1998 are summarized. Descriptive statistics were used to summarize pregnancy and infant outcomes overall, by disease and timing of exposure.

Results As of 23 August 2018, 1850 maternally IFX-exposed pregnancies with known outcomes were identified from the safety database. Of the 1850 pregnancies (mean age 29.7 years), 1526 (82.5\%) resulted in live births. When reported, most women had Crohn's disease (67.7\%) or ulcerative colitis (18.4\%), and $82.8 \%$ of live births were exposed to IFX in the first trimester. Spontaneous abortion/intrauterine death/ectopic pregnancy/molar pregnancy (12.1\%), preterm births $(9.2 \%)$, low birth weight infants (3.6\%), congenital anomalies (2.0\%), and infant infections (1.2\%) were documented. The type of congenital anomalies and frequency of serious infant infections observed were consistent with the general population. Frequencies of congenital anomalies and other adverse outcomes were similar in women exposed to IFX in the first trimester and those exposed in the third trimester. More preterm births (13-18.8\%) and infant complications (8.7-12.5\%) were reported with concomitant immunosuppressant use. Conclusions The observed prevalence of adverse pregnancy and infant outcomes including congenital anomalies following exposure to IFX did not exceed estimates reported for the general population and no unexpected patterns were observed.
\end{abstract}

\section{Introduction}

Inflammatory bowel, rheumatologic, and dermatologic disorders can significantly affect women of childbearing potential. Studies have shown that women with chronic inflammatory disease may experience more adverse pregnancy, birth, and infant outcomes compared with healthy pregnant women [1-4]. Evidence further suggests that untreated disease could lead to disease exacerbation during pregnancy and increase the rate of adverse pregnancy, birth, and infant outcomes [2, 5-8]. However, the treatments available for inflammatory

Anja Geldhof

ageldho1@its.jnj.com

1 Janssen Biologics B.V., Medical Affairs, Einsteinweg 101, 2333 Leiden, CB, The Netherlands

2 Janssen Research and Development, Horsham, PA, USA

3 Janssen Research and Development, Spring House, PA, USA

4 Janssen Research and Development, Titusville, NJ, USA

\section{Key Points}

A total of 8170 reports of innovator infliximab-exposed pregnancies are available in the Janssen global safety surveillance database (safety database). Of those, 1850 were prospective pregnancy reports with known outcomes.

Among the prospectively reported pregnancy reports, the reporting frequency of congenital anomalies did not exceed prevalence estimates for the general population, and no unexpected patterns were observed. Trimester of exposure did not affect the prevalence of congenital anomalies or other adverse outcomes.

Proportions of preterm births and infant complications were numerically higher in women who are exposed to innovator infliximab in combination with conventional systemic immunosuppressants during pregnancy than in the overall exposed population. 
diseases may confer their own risk. An example is methotrexate, which is contraindicated during pregnancy because of teratogenicity [9]. A thorough investigation of the potential risks of the biologic and systemic therapies frequently used to maintain inflammatory disease control during pregnancy is needed. The critical period of organogenesis is the first trimester (T1) of pregnancy during which gestational exposure to teratogenic medications can cause malformations or early fetal wastage [10]. During T1, very little immunoglobulin $\mathrm{G}$ is transported to the fetus because of its molecular size. An active transport mechanism using $\mathrm{Fc}$ receptors becomes functional during the second trimester (T2), generally starting between the 13th and the 26th gestational week [11]. Because maternal immunoglobulin $\mathrm{G}$ crosses the placenta during the third trimester (T3), fetuses are exposed to therapeutic antibodies, potentially influencing their immune system development [12].

Major birth defects occur in 2-4\% of the general population and miscarriage occurs in 15-20\% of clinically recognized pregnancies $[13,14]$. Within the past 20 years, a number of epidemiology studies have reported on the frequency of pregnancy, birth, and infant outcomes among patients exposed to tumor necrosis factor- $\alpha$ inhibitor (TNFi) therapies. These reports document rates of spontaneous abortions ranging from 9.1 to $21.9 \%$, preterm birth from 6.1 to $25 \%$, low birth weight (LBW) from 2.5 to $24 \%$, and congenital anomalies from 1 to $6.3 \%$ (Table 1) [15-28]. Most studies report proportions of patients with events rather than estimate relative risks, potentially because of the limited size of exposed pregnancy cohorts and appropriate comparators, which precludes fully adjusted and sufficiently powered comparisons of risk.

Two meta-analyses, one including 13 observational studies (seven prospective and six retrospective) in pregnant women with immune-mediated diseases [29] and another including eight observational prospective studies in pregnant women with arthritic disease [30], compared the risk of pregnancy and neonatal complications among a group of TNFi users vs. non-TNFi users. Although relative risk estimates for live births and pregnancy-related complications were mostly comparable between the two meta-analyses, findings indicating lower live births (odds ratio 0.61; 95\% confidence interval 0.38-0.98) and an increased risk of infant LBW (relative risk: 1.43; 95\% confidence interval 1.00-2.04) had better precision and reached statistical significance in one of the studies [30]. Point estimates of odds ratios for congenital anomalies, spontaneous or therapeutic abortion, and preterm birth tended to be 1.2 or higher in the two meta-analyses, but confidence intervals were too wide to interpret the results with precision.

Limited data are available for certain infant outcomes, such as infections, hospitalizations, and response to vaccinations, which might be indicators of immune status in infants exposed to an immunomodulator during gestation (Table 1).
Furthermore, although several studies have included the use of infliximab along with other TNFi therapies to study the effect of the TNFi class, very few studies have specifically evaluated the effect of Remicade ${ }^{\circledR}$ (innovator infliximab [IFX]), an immunoglobulin G1 monoclonal antibody, or any other particular TNFi on pregnancy, birth, and infant outcomes. Molecular differences in the antibody constructs might affect placental transfer [31].

Innovator infliximab may be administered in combination with an immunosuppressant such as a corticosteroid, methotrexate, or azathioprine, depending on the disease. Concerns about the safety of this combined treatment approach remain, particularly because congenital anomalies have been associated with corticosteroid [32-34], azathioprine [35], and methotrexate $[36,37]$ use, and preterm birth has been associated with prednisone [38].

Here, we report on birth and infant outcomes (up to 2 years) following gestational exposure to IFX based on a summary of cumulative pregnancy reports in women exposed to IFX during pregnancy from the Janssen global safety database. This analysis represents the largest study to date investigating the outcomes of exposure to IFX during pregnancy.

\section{Methods}

\subsection{Data Source and Study Design}

The manufacturer of Remicade ${ }^{\circledR}$ (Janssen Pharmaceuticals, LLC, Horsham, USA) maintains a global safety database that includes all safety events reported from any source for patients receiving IFX since its first marketing approval in 1998. All pregnancies reported to the company from clinical trials, postmarketing studies, and voluntary reports are included in the safety database. Reports may be prospective (pregnancy with IFX exposure reported to the company before the pregnancy outcome is known) or retrospective (pregnancy and outcome reported simultaneously; includes outcomes assessed based on prenatal testing, such as an ultrasound). For all spontaneous reports (prospective or retrospective) of IFX-exposed pregnancies, two follow-up attempts via telephone, fax, mail, or e-mail were made, regardless of validity, seriousness, expectedness, or causal relationship. For IFX-exposed pregnancies reported prospectively with unknown outcome at the time of the initial report, two additional follow-up attempts were made to obtain pregnancy outcome information. Although both prospective and retrospective reports are available, this analysis focused on prospectively reported pregnancies because pregnancy reports submitted retrospectively are subject to reporting bias (adverse pregnancy outcomes are more often reported than uneventful pregnancies) and are therefore unreliable for estimating rates of specific outcomes. Because 
Table 1 Prevalence of infant and birth outcomes in women exposed to tumor necrosis factor- $\alpha$ inhibitor (TNFi)

\begin{tabular}{|c|c|c|c|c|c|c|c|c|}
\hline \multirow[t]{2}{*}{ Study, year } & \multirow{2}{*}{$\begin{array}{l}\text { Study design/ } \\
\text { indication(s) }\end{array}$} & \multirow[t]{2}{*}{ TNFi } & \multicolumn{3}{|l|}{ Birth (\%) } & \multicolumn{3}{|c|}{ Infant (\%) } \\
\hline & & & $\begin{array}{l}\text { Spontane- } \\
\text { ous abor- } \\
\text { tions }\end{array}$ & Preterm birth & LBW & $\begin{array}{l}\text { CA/ } \\
\text { birth } \\
\text { defects }\end{array}$ & Infections & Mortality \\
\hline $\begin{array}{l}\text { Schnitzler et al. (2011) } \\
\text { [22] }\end{array}$ & Retrospective/IBD & IFX, ADA & - & 25.0 & 18.8 & - & - & - \\
\hline $\begin{array}{l}\text { Casanova et al. (2013) } \\
\text { [18] }\end{array}$ & Retrospective/IBD & IFX, ADA, CTZ & 9.1 & 6.1 & 8.5 & 1.7 & 3.0 & 0 \\
\hline $\begin{array}{l}\text { Diav-Citrin et al. (2014) } \\
\text { [20] }\end{array}$ & Prospective/multiple ${ }^{\mathrm{a}}$ & IFX, ADA, ETN & - & 22.7 & - & 4.6 & - & - \\
\hline Seirafi et al. (2014) [23] & Case control/IBD & IFX, ADA, CTZ & - & 20.0 & 16.0 & 1.0 & 2.0 & 1.0 \\
\hline $\begin{array}{l}\text { Cooper et al. (2014) } \\
\text { [19] }\end{array}$ & Retrospective/multiple ${ }^{\mathrm{b}}$ & IFX, ADA, ETN & - & - & - & $3.6^{\mathrm{c}}$ & - & 0 \\
\hline $\begin{array}{l}\text { Komoto et al. (2016) } \\
\text { [21] }\end{array}$ & Cross-sectional/IBD & IFX, ADA & 17.7 & 8.0 & 24.0 & 2.9 & - & - \\
\hline $\begin{array}{l}\text { Bröms et al. (2016) } \\
\text { [25] }\end{array}$ & Retrospective/multiple ${ }^{\mathrm{c}}$ & $\begin{array}{l}\text { IFX, ADA, ETN, GOL, } \\
\text { CTZ }\end{array}$ & - & - & - & 6.3 & - & - \\
\hline $\begin{array}{l}\text { Chambers et al. (2017) } \\
\text { [15] }\end{array}$ & Retrospective/multiple $^{\mathrm{d}}$ & Not specified & - & - & - & - & $4.0^{\mathrm{e}}$ & - \\
\hline $\begin{array}{l}\text { Burmester et al. (2017) } \\
\text { [16] }\end{array}$ & Pregnancy registry/RA & ADA & - & - & - & 4.2 & - & - \\
\hline $\begin{array}{l}\text { Carman et al. (2017) } \\
\text { [17] }\end{array}$ & Retrospective/CIA & ETN & 21.9 & 19.3 & 15.1 & 6.1 & - & - \\
\hline $\begin{array}{l}\text { Carman et al. (2017) } \\
\text { [17] }\end{array}$ & Retrospective/PSO & ETN & 16.0 & 15.7 & 11.8 & 2.0 & - & - \\
\hline $\begin{array}{l}\text { Kammerlander et al. } \\
\text { (2017) [24] }\end{array}$ & Retrospective/IBD & IFX, ADA, CTZ & - & $\begin{array}{l}17.8^{\mathrm{f}} \\
7.5^{\mathrm{g}}\end{array}$ & $\begin{array}{l}12.3^{\mathrm{f}} \\
2.5^{\mathrm{g}}\end{array}$ & - & - & - \\
\hline $\begin{array}{l}\text { Chaparro et al. (2018) } \\
\text { [26] }\end{array}$ & Retrospective/IBD & IFX, ADA, CTZ & - & 10.6 & 10.6 & 5.4 & 12 & - \\
\hline $\begin{array}{l}\text { Lichtenstein et al. } \\
\text { (2018) [27] }\end{array}$ & Prospective registry/CD & IFX & 16.2 & - & - & 1.2 & - & - \\
\hline Vinet et al. (2018) [28] & Retrospective/RA & $\begin{array}{l}\text { IFX, ADA, ETN, CTZ, } \\
\text { GOL }\end{array}$ & - & - & - & - & 3.2 & - \\
\hline
\end{tabular}

Prevalence of infant and birth outcomes are reported by study, if data were available

$A D A$ adalimumab, $A S$ ankylosing spondylitis, $C A$ congenital anomaly, $C D$ Crohn's disease, $C I A$ chronic inflammatory arthritis, $C T Z$ certolizumab, ETN etanercept, $G O L$ golimumab, $I B D$ inflammatory bowel disease, $I F X$ innovator infliximab, $L B W$ low birth weight, $P S A$ psoriatic arthritis, $P S O$ psoriasis, $R A$ rheumatoid arthritis, $U C$ ulcerative colitis

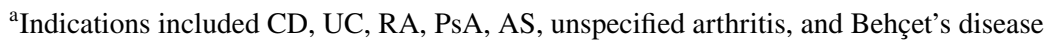

${ }^{b}$ Indications included RA, PsA, AS, systemic lupus erythematosus, scleroderma, inflammatory myopathies, mixed connective tissue disorders, and IBD

${ }^{\mathrm{c}}$ Indications included IBD, RA, AS, PsA, and PSO

${ }^{\mathrm{d}}$ Indications included RA, systemic lupus erythematosus, AS, PsA, and IBD

${ }^{\mathrm{e}}$ Any infection following exposure to any biologic therapy

${ }^{\mathrm{f}}$ Proportion of birth outcome in women with clinical disease activity during pregnancy (TNFi exposure during third trimester)

${ }^{\mathrm{g}}$ Proportion of birth outcome in women without clinical disease activity during pregnancy (TNFi exposure during third trimester)

paternal exposure to TNFi is generally considered not to pose a significant risk for adverse pregnancy outcomes [39-43], paternally exposed pregnancies were beyond the scope of this analysis. This analysis also did not attempt to evaluate outcomes in neonates potentially exposed via lactation.

The main analysis included medically confirmed reports (with information provided by healthcare professionals) of maternal exposure to IFX during pregnancy or prior to conception, with a known birth outcome reported to the company through 23 August 2018. When available, information on demographics, indication for IFX use, concomitant medications, timing of IFX exposure during or prior to gestation, and the pregnancy course and outcome was obtained. First- and third-trimester exposures were calculated based 
on the time of IFX exposure relative to gestation. The date of conception was not always available. Therefore, this date was extrapolated from the date of the last menstrual period, date of birth, or pregnancy due date [44].

\subsection{Analysis}

Data were summarized overall and by disease group (rheumatologic combined [rheumatoid arthritis, psoriatic arthritis, and ankylosing spondylitis], inflammatory bowel disease [IBD] individually [Crohn's disease and ulcerative colitis], and psoriasis) and analyzed by timing of exposure. In addition, available data on maternal demographics, timing of drug administration relative to conception date, concomitant medications, pregnancy course, and outcome were summarized. Birth outcomes were defined as follows: preterm births, $<37$ completed weeks; LBW, $\geq 1500 \mathrm{~g}$ to $<2500 \mathrm{~g}$; and very LBW, $<1500$ g. For infant outcomes (up to 2 years), neonatal infections included both serious and nonserious infections. Serious adverse events (AEs) were defined as any AE that required an inpatient or prolonged hospitalization, resulted in persistent or significant disability or incapacity, was a congenital anomaly/birth defect, was life threatening or medically important, or resulted in death $[45,46]$. Serious AEs excluding congenital anomalies were further categorized into (1) serious infections, (2) all serious AEs excluding birth outcomes, and (3) all serious AEs excluding birth outcomes and serious infections. Birth outcomes were classified as small for gestational age (SGA) only if they were reported as such in the safety database by the reporter (i.e., based on the verbatim term). No other formal criteria were applied to define SGA among infants. Congenital anomalies include a range of abnormalities of body structure or function that are present at birth and are of prenatal origin [47]. Based on guidance by Centers for Disease Control and Prevention, major congenital anomalies were defined as structural changes that have significant medical, social, or cosmetic consequences for the affected individual and typically require medical intervention [47]. Descriptive data for outcomes are presented as the number and proportion for relevant patient subgroups unless otherwise specified in summary tables. As spontaneous safety reports are, by definition, voluntarily reported, they are generally limited by missing data, and statistical comparisons across therapies cannot be made.

\section{Results}

\subsection{Overview of Pregnancies}

An overview of the pregnancy reports of women exposed to IFX is shown in Fig. 1. A total of 8170 reports of IFXexposed pregnancies were entered in the IFX global safety database through 23 August 2018, with 6881 reports of maternal exposure and 1289 reports of paternal exposure. Of the maternally exposed pregnancies, most were reported prospectively $(n=5160)$. The outcomes were reported for $1850 / 5160(35.9 \%)$ of these prospective reports and for $1711 / 1725$ (99.2\%) of retrospective pregnancy reports. Among the known outcomes of the prospective reports, there were 1526/1850 (82.5\%) reports resulting in 1549 live births reported. The 1725 retrospective reports, resulting in 1731 known outcomes, included 1196/1731 (69.1\%) live births (among which 100/1196 [8.4\%] infants were born with a congenital anomaly, and 138/1196 [11.5\%] infants had AEs other than a congenital anomaly), 392/1731 (22.6\%) spontaneous abortions, and 113/1731 (6.5\%) elective abortions.

\subsection{Prospective Reports of Maternal-Exposed Pregnancies}

\subsubsection{Maternal Demographic and Exposure Characteristics}

At the conclusion of the cumulative data analysis period, a total of 1850 prospectively reported, medically confirmed, IFX maternally exposed pregnancies with known outcomes were identified from the safety database (Table 2). Most reports originated from observational studies $(59.5 \%)$ or from spontaneous reports (34.9\%; Table 2). The majority of the 1850 pregnant women were reported from North America, primarily from Canada (51.4\%) where most (90-95\%) of the patients receiving IFX are managed through a manufacturer-sponsored patient support program, facilitating prospective data collection on all pregnancies [48], and from the USA (16.8\%) where TNFi traditionally has a high uptake. The mean maternal age was 29.7 years. The distribution of diseases being treated, when reported $(n=1752)$, was as follows: 1186 (67.7\%) with Crohn's disease, 322 (18.4\%) with ulcerative colitis, 128 (7.3\%) with rheumatoid arthritis/ankylosing spondylitis/psoriatic arthritis, and 42 (2.4\%) with psoriasis (Table 3); the remaining 74 outcomes (4.2\%) reported maternal disease not approved for treatment with IFX (other indications included IBD, Behcet's syndrome, and hidradenitis suppurativa). For 123 birth outcomes, the maternal disease indication was not reported.

Of the 1850 pregnant women, $1357(73.4 \%)$ reported the trimester of exposure to IFX (Table 2): 85 (6.3\%) were exposed within 2 months prior to the calculated conception date, 602 (44.4\%) during T1 only, 1210 (89.1\%) during T1 (all T1; defined as women who may have been exposed to IFX during T1 as well as other trimester[s]), 507 (37.4\%) during T3 (all T3; defined as women who may have been exposed to IFX during T3 as well as other trimester[s]), and 464 (34.2\%) were exposed throughout their pregnancy (T1 through $\mathrm{T} 3$ ). Among all live births, a total of 495 (32.0\%) unique women reported exposure to at least one other immunosuppressant 


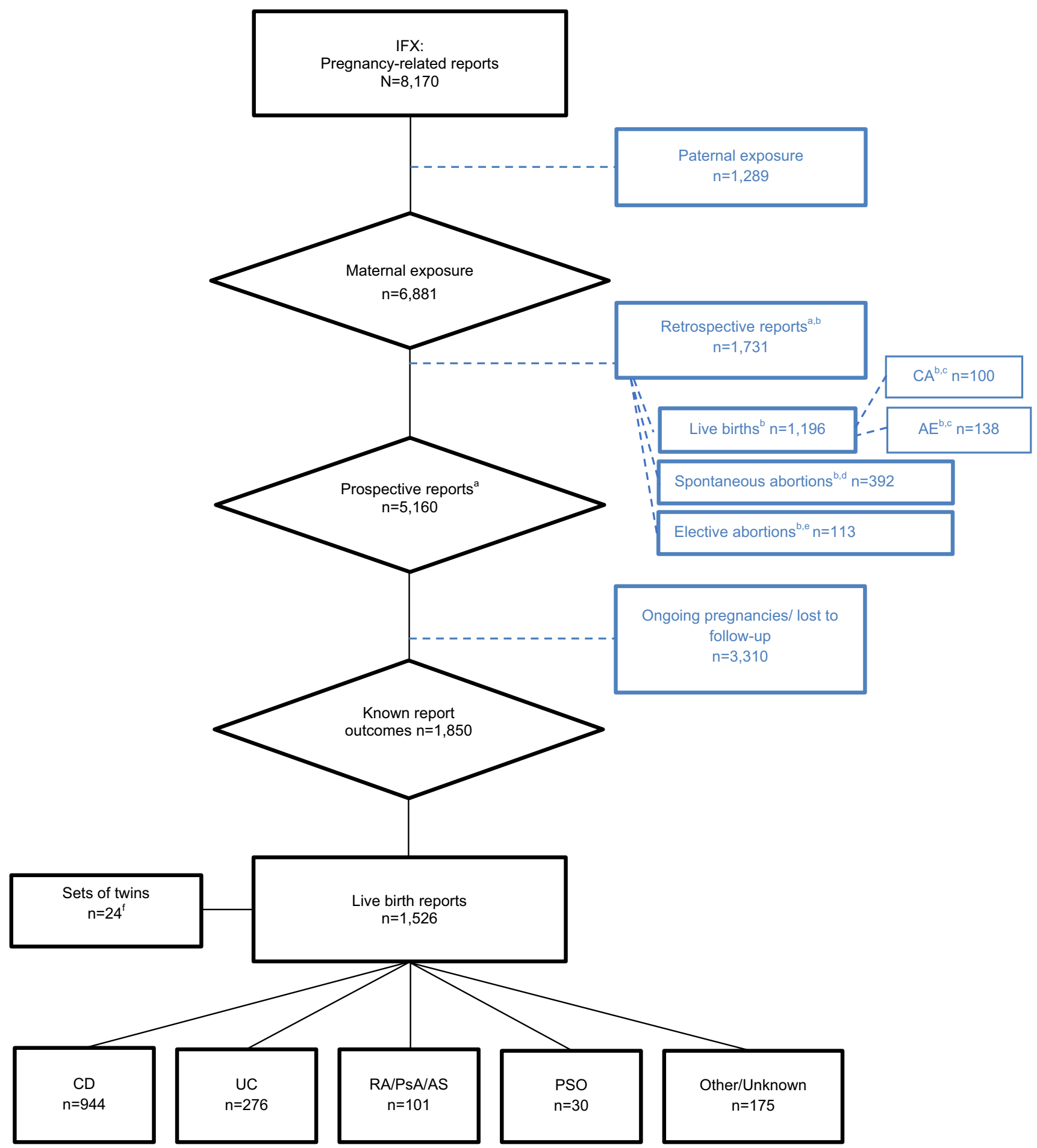

Fig. 1 Overview of pregnancy reports exposed to innovator infliximab (IFX). $A E$ adverse event, $A S$ ankylosing spondylitis, $C A$ congenital anomaly, $C D$ Crohn's disease, $N$ overall sample size, $n$ number of patients, $P S A$ psoriatic arthritis, $P S O$ psoriasis, $R A$ rheumatoid arthritis, $U C$ ulcerative colitis. ${ }^{\text {a }}$ Four reports noted both prospective and retrospective pregnancies. ${ }^{b}$ Retrospective reports are presented at the outcome level. ' $\mathrm{Six}$ reports noted CAs along with other AEs; hence, the count for these reports has been included in both the CA and other AE categories; however, they have only been counted once in the total live birth outcome. ${ }^{\mathrm{d}}$ Three reports noted twin pregnancies with the outcome of spontaneous abortion. ${ }^{\mathrm{e}}$ Abortion missed has been included in this category. ${ }^{\mathrm{f}}$ This includes 23 twin reports of live birth and one twin report with the outcome of live birth and spontaneous abortion 
during pregnancy: 299 (60.4\%) reported gestational exposure to azathioprine or 6-mercaptopurine, 245 (49.5\%) to corticosteroids, and $32(6.5 \%)$ to methotrexate (Table 2).

\subsubsection{Birth Outcomes}

Of the 1875 birth outcomes studied (24 pregnancy reports noted twin pregnancies), 226 (12.1\%) were spontaneous abortion/intrauterine death/ectopic pregnancies/molar pregnancies, and 81 (4.3\%) were elective abortions (Table 3). Among the 1549 live births in women with IFX exposure (across all indications), the most frequently reported adverse birth outcomes included $143(9.2 \%)$ preterm births and 55 (3.6\%) LBW infants (Table 3). The prevalence of all other birth outcomes (very LBW, SGA/intrauterine growth retardation) was $\leq 1.1 \%$ (Table 3 ). For birth outcomes by indication, women with psoriasis had the lowest proportion of preterm births (6.5\%; Table 3$)$ and the lowest prevalence of spontaneous abortion, intrauterine death, ectopic pregnancies, and molar pregnancies $(9.5 \%$; Table 3$)$. The proportion of women who had preterm births was similar among women with Crohn's disease (10.0\%), ulcerative colitis (9.6\%), and rheumatologic indications (9.6\%). The prevalence of LBW infants was highest among women with Crohn's disease (4.5\%) (Table 3).

Among IFX-exposed pregnancies resulting in spontaneous abortion, intrauterine death, ectopic pregnancies, molar pregnancies, preterm birth, (very) LBW, and SGA/intrauterine growth retardation, proportions of these outcomes in subsets of women reporting concomitant use of immunosuppressants (especially methotrexate) were numerically higher than those observed in the overall IFX-exposed population in the analysis

Table 2 Infliximab (IFX) pregnancy report characteristics

\begin{tabular}{|c|c|}
\hline Overall reports ${ }^{\mathrm{a}}$ & $N=1850$ \\
\hline Age, mean (SD) & $29.7(0.1)$ \\
\hline \multicolumn{2}{|l|}{ Source } \\
\hline Solicited & $1101(59.5)$ \\
\hline Spontaneous & $645(34.9)$ \\
\hline Clinical & $78(4.2)$ \\
\hline Literature & $26(1.4)$ \\
\hline \multicolumn{2}{|l|}{ Origin of reports ${ }^{\mathrm{b}}$} \\
\hline Canada & $951(51.4)$ \\
\hline USA & $311(16.8)$ \\
\hline France & $104(5.6)$ \\
\hline Trimester of exposure to IFX & $1357(73.4)$ \\
\hline T0 & $85(6.3)$ \\
\hline T1 only ${ }^{\mathrm{c}}$ & $602(44.4)$ \\
\hline All T1 ${ }^{\mathrm{d}}$ & $1210(89.1)$ \\
\hline All T3 & $507(37.4)$ \\
\hline $\mathrm{T} 1, \mathrm{~T} 2$, and $\mathrm{T} 3$ & $464(34.2)$ \\
\hline Live births $^{\mathrm{e}}$ & $N=1549$ \\
\hline Concomitant immunosuppressants & $495(32)$ \\
\hline Azathioprine or 6-mercaptopurine & $299(60.4)$ \\
\hline Corticosteroids & $245(49.5)$ \\
\hline Methotrexate & $32(6.5)$ \\
\hline
\end{tabular}

Data are presented as $n(\%)$ unless otherwise specified. Indented case characteristics are displayed as a percentage of the last characteristic not indented, except for concomitant immunosuppressants, which are based on the total number of live births $(N=1549)$

$N$ overall sample size, $n$ number of patients, $S D$ standard deviation, $T 0$ exposure to infliximab within 2 months prior to the calculated conception date, $T 1$ first trimester, $T 2$ second trimester, $T 3$ third trimester

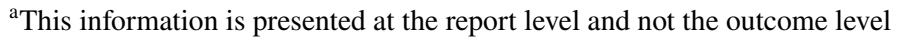

${ }^{\mathrm{b}}$ Countries with $\mathrm{a} \geq 5 \%$ incidence of pregnancy reports are displayed

${ }^{\mathrm{c}}$ Includes patients who were only exposed to IFX during the first trimester

${ }^{\mathrm{d}}$ Includes patients who may have been exposed to IFX during the first trimester as well as other trimester(s)

${ }^{\mathrm{e}}$ Twenty-four reports noting twin pregnancies. This includes 23 reports noting a live birth outcome and 1 report noting 2 different pregnancy outcomes, i.e., live birth and spontaneous abortion 
Table 3 Birth and infant outcomes of innovator infliximab pregnancy reports for overall, by indications, and trimester of exposure

\begin{tabular}{|c|c|c|c|c|c|c|c|}
\hline Type, $n(\%)$ & Overall $^{\mathrm{a}}(N=1875)$ & $\mathrm{CD}^{\mathrm{a}}(N=1186)$ & $\mathrm{UC}^{\mathrm{a}}(N=322)$ & $\begin{array}{l}\text { RA/AS/ } \\
\text { PsA }^{\mathrm{a}} \\
(N=128)\end{array}$ & $\operatorname{PSO}^{\mathrm{a}}(N=42)$ & $\begin{array}{l}\text { Overall, T1 } \\
\text { exposure }^{\mathrm{a}, \mathrm{b}} \\
(N=1300)\end{array}$ & $\begin{array}{l}\text { Overall, T3 } \\
\text { exposure }^{\mathrm{a}} \\
(N=507)\end{array}$ \\
\hline Live births $^{c}$ & 1549 (82.6) & $956(80.6)$ & $281(87.2)$ & $104(81.3)$ & $31(73.8)$ & $1076(82.8)$ & $501(98.8)$ \\
\hline \multicolumn{8}{|l|}{ Birth outcomes } \\
\hline Preterm births ${ }^{\mathrm{d}}$ & $143(9.2)$ & $96(10)$ & $27(9.6)$ & $10(9.6)$ & $2(6.5)$ & $111(10.3)$ & $50(10)$ \\
\hline Low birth weight $\mathrm{e}^{\mathrm{e}}$ & $55(3.6)$ & $43(4.5)$ & $5(1.8)$ & $2(1.9)$ & $1(3.2)$ & $38(3.5)$ & $15(3.0)$ \\
\hline Very low birth weight ${ }^{f}$ & $17(1.1)$ & $10(1.0)$ & $3(1.1)$ & $4(3.8)$ & 0 & $11(1.0)$ & $1(<1.0)$ \\
\hline $\begin{array}{l}\text { Small for gestational } \\
\text { age/intrauterine } \\
\text { growth retardation }\end{array}$ & $10(<1.0)$ & $8(<1.0)$ & 0 & 0 & 0 & $7(<1.0)$ & $3(<1.0)$ \\
\hline \multicolumn{8}{|l|}{ Infant outcomes } \\
\hline $\begin{array}{l}\text { Adverse events } \\
\text { (excluding congenital } \\
\text { anomaly) }\end{array}$ & $111(7.2)$ & $66(6.9)$ & $13(4.6)$ & $9(8.7)$ & $4(12.9)$ & $76(7.1)$ & $35(7)$ \\
\hline Neonatal infection $^{\mathrm{h}}$ & $19(1.2)$ & $6(<1.0)$ & $1(<1.0)$ & $2(1.9)$ & 0 & $11(1.0)$ & $4(<1.0)$ \\
\hline $\begin{array}{l}\text { Serious adverse events } \\
\text { (excluding congeni- } \\
\text { tal anomaly) }\end{array}$ & $89(5.7)$ & $52(5.4)$ & $9(3.2)$ & $7(6.7)$ & $3(9.7)$ & $60(5.6)$ & $25(5)$ \\
\hline Neonatal infection & $16(1.0)$ & $4(<1.0)$ & $1(<1.0)$ & $1(1.0)$ & 0 & $9(<1.0)$ & $2(<1.0)$ \\
\hline $\begin{array}{l}\text { Other serious } \\
\text { adverse events, } \\
\text { (excluding birth } \\
\text { outcomes/includ- } \\
\text { ing infections) }\end{array}$ & $72(4.6)$ & $39(4.1)$ & $7(2.5)$ & $7(6.7)$ & $3(9.7)$ & $51(4.7)$ & $20(4)$ \\
\hline $\begin{array}{l}\text { Other serious } \\
\text { adverse events, } \\
\text { (excluding birth } \\
\text { outcomes and } \\
\text { infections) }\end{array}$ & $56(3.6)$ & $35(3.7)$ & $6(2.1)$ & $6(5.8)$ & $3(9.7)$ & $42(3.9)$ & $18(3.6)$ \\
\hline Congenital anomaly & $31(2.0)$ & $18(1.9)$ & $1(<1.0)$ & $6(5.8)$ & 0 & $20(1.9)$ & $11(2.2)$ \\
\hline \multicolumn{8}{|l|}{ Non-live birth } \\
\hline $\begin{array}{l}\text { Spontaneous abortion/ } \\
\text { intrauterine death/ } \\
\text { ectopic/molar }\end{array}$ & $226^{\mathrm{j}, \mathrm{k}}(12.1)$ & $166^{\mathrm{j}, \mathrm{k}}(14.0)$ & $32^{1}(9.9)$ & $15(11.7)$ & $4(9.5)$ & $161^{\mathrm{k}, \mathrm{m}}(12.4)$ & $6(1.2)$ \\
\hline $\begin{array}{l}\text { Small for gestational }{ }^{\mathrm{n}} \\
\text { age/intrauterine } \\
\text { growth retardation }^{\mathrm{o}}\end{array}$ & $1(<1.0)$ & $1(<1.0)$ & 0 & 0 & 0 & 0 & 0 \\
\hline $\begin{array}{l}\text { Elective/induced abor- } \\
\text { tion }\end{array}$ & $81(4.3)$ & $49(4.1)$ & $8(2.5)$ & $8(6.3)$ & $6(14.3)$ & $52(4.0)$ & 0 \\
\hline $\begin{array}{l}\text { Abortion scheduled/ } \\
\text { abortion unspecified }\end{array}$ & $14(<1.0)$ & $10(<1.0)$ & $1(<1.0)$ & $1(<1.0)$ & $1(2.4)$ & $7(<1.0)$ & 0 \\
\hline Stillbirth & $2(<1.0)$ & $2(<1.0)$ & 0 & 0 & 0 & $1(<1.0)$ & 0 \\
\hline
\end{tabular}

All data are presented as $n(\%)$. Cumulative data collected through 23 August 2018 are reported. Infant mortality was not captured in the Global Medical Safety database

$A E$ adverse event, $A S$ ankylosing spondylitis, $C D$ Crohn's disease, $N$ number of pregnancies with known outcomes, $n$ number of patients, $P s A$ psoriatic arthritis, $P S O$ psoriasis, $R A$ rheumatoid arthritis, $T O$ exposure to infliximab within 2 months prior to the calculated conception date, $T 1$ first trimester, $T 3$ third trimester, $U C$ ulcerative colitis

${ }^{a}$ These reports represent a subset of the total number of reports $(n=5160)$. This includes 23 twin reports of live birth and 1 twin report with the outcome of both live birth and spontaneous abortion; hence, the count has been presented based on the number of birth outcomes and non-live birth outcomes, as appropriate. One report reported 2 pregnancy outcomes, i.e., spontaneous abortion for both pregnancies; hence, the count has been presented based on the number of non-live birth outcomes. Count also includes 3 reports of cesarean births scheduled with unknown outcomes. In addition, this count includes 74 outcomes (4.2\%) that reported maternal disease not approved for treatment with IFX (other indications included inflammatory bowel disease, Behcet's syndrome, and hidradenitis suppurativa). For 123 birth outcomes, the maternal disease indication was not reported

${ }^{\mathrm{b}}$ The count also includes T0 reports, where exposure to infliximab was reported up to 2 months prior to conception

${ }^{\mathrm{c}}$ Twenty-four reports noted twin pregnancies. This includes 23 reports noting a live birth outcome and 1 report noting 2 pregnancy outcomes, 
Table 3 (continued)

i.e., live birth and spontaneous abortion

${ }^{\mathrm{d}}$ Preterm births were defined as $<37$ weeks

${ }^{\mathrm{e}}$ Low birth weight was defined as $\geq 1500 \mathrm{~g}$ to $<2500 \mathrm{~g}$ in the safety surveillance database

${ }^{\mathrm{f}}$ Very low birth weight was defined as $<1500 \mathrm{~g}$ in the safety surveillance database

${ }^{\mathrm{g}}$ Three twin reports also reported congenital anomalies along with other AEs. Three additional reports reported congenital anomalies and other AEs in a single pregnancy outcome; hence, the count for these 3 reports has been included in both the congenital anomaly and other AE categories. Some of these reports also include birth outcomes, such as preterm births, low birth weight, very low birth weight, and small for gestational age

${ }^{\mathrm{h}}$ This count includes both serious and nonserious reports

${ }^{\mathrm{i}}$ This excludes birth outcomes such as preterm births, low birth weight, very low birth weight, and small for gestational age. This includes serious infections

${ }^{\mathrm{j}}$ This includes a total of 12 ectopic and 1 molar pregnancies. In addition, it includes 1 twin pregnancy with the outcome of spontaneous abortion for 1 of the twins and 1 report with 2 pregnancies reporting spontaneous abortion as the outcome for both pregnancies

${ }^{\mathrm{k}}$ Two IFX-exposed women with spontaneous abortions reported congenital malformations. One report of spontaneous abortion also reported small for gestational age/intrauterine growth retardation

${ }^{\mathrm{I}}$ This includes a total of 4 ectopic pregnancies

${ }^{\mathrm{m}}$ This includes a total of 8 ectopic and 1 molar pregnancies

${ }^{\mathrm{n}}$ The overall population included 1 molar pregnancy, 12 ectopic pregnancies, and a combined total of 213 spontaneous abortions/intrauterine deaths

${ }^{\circ}$ This report is a subset of spontaneous abortion/intrauterine death/ectopic/molar pregnancies

(Table 4). In particular, more preterm births (13-18.8\%) were reported with concomitant immunosuppressant use than the overall IFX-exposed study population $(9.2 \%)$.

\subsubsection{Infant Outcomes}

Of the 1875 birth outcomes in the analysis dataset, 1549 $(82.6 \%)$ were reported as resulting in live births (Table 3 ). Among the live births, $31(2.0 \%)$ infants with congenital anomalies and $111(7.2 \%)$ infants with other AEs (excluding congenital anomalies) were reported among neonates (Table 3). Twenty-six major congenital anomalies and 15 minor congenital anomalies were reported in 31 live births (Table 5). Nineteen (1.2\%) of the other AEs were reported to be neonatal infections (Table 3). Eighty-nine of the AEs (excluding congenital anomalies) were deemed serious including 16 serious neonatal infections (Table 3). These adverse infant outcomes were reported in a numerically higher proportion of women with known concomitant immunosuppressant use during their pregnancy than observed in the overall IFX-exposed population (Table 4). When infant outcomes were considered by indication (Table 3), a higher proportion of infants with AEs was reported among women with psoriasis (12.9\%) than among women with Crohn's disease $(6.9 \%)$, ulcerative colitis $(4.6 \%)$, or rheumatoid arthritis/ankylosing spondylitis/psoriatic arthritis (8.7\%). However, no congenital anomalies were reported from women with psoriasis exposed to IFX. Live births with congenital anomalies were reported less frequently among women with Crohn's disease $(1.9 \%)$ and ulcerative colitis $(<1.0 \%)$ than among women with rheumatologic indications $(5.8 \%)$.
Two stillbirths ( $<1.0 \%$ of all pregnancy reports) were also reported, both of which occurred in women with Crohn's disease (Table 3).

A total of $1076(82.8 \%)$ pregnancies with IFX exposure in $\mathrm{T} 1$ resulted in live births, from which $20(1.9 \%)$ infants had congenital anomalies and $76(7.1 \%)$ infants were reported to have other AEs (Table 3). Likewise, 501 (98.8\%) pregnancies with IFX exposure in T3 resulted in live births with similar proportions of infants with congenital anomalies $(2.2 \%)$ and other AEs (7\%) reported (Table 3). The prevalence of infants with congenital anomalies or other AEs following T1 and T3 exposure was comparable to rates observed for the overall population (Table 3). For a total of 11 congenital anomalies, trimester exposure was not reported for eight infants, and three infants with congenital anomalies were not exposed to IFX in T1 (data not shown). An additional six congenital anomalies (four major congenital anomalies and two minor congenital anomalies) among five abortions (spontaneous, elective, or induced abortions; abortion unspecified; and abortion scheduled) were reported (Table 5). Congenital anomalies that occurred more than once, including hypospadias [49], septal defects [50], and Down syndrome [51], are among the more commonly reported congenital anomalies in general. In addition, there were three infants with gastroschisis. Two of the three reports involved two different pregnancies in the same woman with Crohn's disease and ankylosing spondylitis, and the third report was in a 23-year-old woman with Crohn's disease. Some neonates were reported to have more than one congenital anomaly, but none of the prospective reports were determined to be of the VATER/VACTERL association of congenital malformations [52-54]. Based on data available 
Table 4 Birth and infant outcomes in pregnancy reports for overall and by concomitant immunosuppressant

\begin{tabular}{|c|c|c|c|c|}
\hline Type, $n(\%)$ & Overall $^{\mathrm{a}}(N=1875)$ & AZA/6-MP $(N=370)$ & $\operatorname{MTX}(N=51)$ & $\begin{array}{l}\text { Corti- } \\
\text { costeroid } \\
(N=287)\end{array}$ \\
\hline Live births $s^{a, b}$ & 1549 & $299(80.8)$ & $32(62.7)$ & $245(85.4)$ \\
\hline \multicolumn{5}{|l|}{ Birth outcomes } \\
\hline Preterm births & $143(9.2)$ & $39(13.0)$ & $6(18.8)$ & $36(14.7)$ \\
\hline Low birth weight $(<2500 \mathrm{~g})$ & $55(3.6)$ & $11(3.7)$ & $2(6.3)$ & $21(8.6)$ \\
\hline Very low birth weight $(<1500 \mathrm{~g})$ & $17(1.1)$ & $4(1.3)$ & $3(9.4)$ & $5(2.0)$ \\
\hline Small for gestational age/intrauterine growth retardation & $10(<1.0)$ & $3(1.0)$ & $1(3.1)$ & $3(1.2)$ \\
\hline \multicolumn{5}{|l|}{ Infant outcomes } \\
\hline AEs (excluding congenital anomalies) ${ }^{c}$ & $111(7.2)$ & $26(8.7)$ & $4(12.5)$ & $27(11.0)$ \\
\hline Neonatal infection & $19(1.2)$ & $4(1.3)$ & $1(3.1)$ & $3(1.2)$ \\
\hline Serious AEs & $89(5.7)$ & $22(7.4)$ & $4(12.5)$ & $23(9.4)$ \\
\hline Neonatal infection & $16(1.0)$ & $3(1.0)$ & $1(3.1)$ & $3(1.2)$ \\
\hline Other serious events (excluding birth outcomes) ${ }^{\mathrm{d}}$ & $72(4.6)$ & $18(6.0)$ & $3(9.4)$ & $19(7.8)$ \\
\hline Other serious events (excluding birth outcomes ${ }^{\mathrm{d}}$ and infections) & $56(3.6)$ & $15(5.0)$ & $2(6.3)$ & $16(6.5)$ \\
\hline Congenital anomalies & $31(2.0)$ & $9(3.0)$ & $5(15.6)$ & $9(3.7)$ \\
\hline Non-live birth ${ }^{\mathrm{e}}$ & $326^{f}$ & 71 (19.2) & $19(37.3)$ & 42 (14.6) \\
\hline Spontaneous abortion/intrauterine death/ectopic/molar & $226(12.1)$ & $48(13.0)$ & $15(29.4)$ & $29(10.1)$ \\
\hline Small for gestational age/intrauterine growth retardation ${ }^{\mathrm{g}}$ & $1(<1.0)$ & $1(2.1)$ & 0 & $1(3.4)$ \\
\hline Elective/induced abortion & $81(4.3)$ & $21(5.7)$ & $3(5.9)$ & $11(3.8)$ \\
\hline Abortion scheduled/abortion unspecified & $14(<1.0)$ & $2(<1.0)$ & $1(2.0)$ & $2(<1.0)$ \\
\hline Stillbirth & $2(<1.0)$ & 0 & 0 & 0 \\
\hline
\end{tabular}

All data are reported as $n(\%)$. Infant mortality was not captured in the Global Medical Safety database

6-MP 6-mercaptopurine, $A E$ adverse event, $A Z A$ azathioprine, $M T X$ methotrexate, $N$ overall sample size, $n$ number of patients

${ }^{a}$ Twenty-four reports noted twin pregnancies. This includes 23 reports noting a live birth outcome and 1 report noting 2 pregnancy outcomes, i.e., live birth and spontaneous abortion. However, the count of medications has been captured at the pregnancy report level $(n=1850)$

${ }^{b}$ Percentage calculated as a fraction, i.e., same birth outcome over all live births reporting same medication

${ }^{\mathrm{c}}$ AEs were defined as any live birth with an incident outcome with an AE pertaining to an infant. Additionally, 3 twin reports also noted congenital anomalies along with other AEs. Three additional reports noted congenital anomalies and other AEs in a single pregnancy outcome; hence, the count for these 3 reports has been included in both the congenital anomaly and other AE categories

${ }^{\mathrm{d}}$ This excludes birth outcomes such as preterm births, low birth weight, very low birth weight, and small for gestational age. This includes serious infections

${ }^{\mathrm{e}}$ Percentage calculated as a fraction, i.e., same non-live birth outcome over all birth outcomes reporting same medication

${ }^{\mathrm{f}}$ Overall count also includes 3 reports of cesarean births scheduled with unknown outcomes. This includes 1 report with 2 pregnancies reporting spontaneous abortion as the outcome for both pregnancies. However, the count of medications has been captured at the pregnancy report level $(n=1850)$

${ }^{\mathrm{g}}$ This category is a subset of spontaneous abortion/intrauterine death/ectopic/molar and the percentages have been calculated as a fraction of these cases

in the safety database, higher frequencies of AEs in infants (8.7-12.5\%) were observed in women exposed to concomitant immunosuppressants during pregnancy than observed in the overall IFX-exposed population (7.2\%), although no formal statistical comparison tests were conducted (Table 4).

\section{Discussion}

An estimated 2.9 million patients were treated with IFX (Remicade) worldwide through 23 August 2018 [55]. However, despite its widespread use, the effect of IFX in pregnant women is still not fully understood. Two smaller studies describing the outcomes of IFX-exposed pregnancies were previously published. In 2004, an early analysis from the safety database reported on 96 IFX maternally exposed pregnancies [56]. In a report from the TREAT Registry in Crohn's disease, pregnancy outcomes were described for 324 pregnancies, of which 99 were from women with gestational exposure to IFX [27]. To date, the current analysis represents the largest study investigating birth and infant outcomes (up to 2 years) by providing a cumulative analysis of pregnancy reports with gestational exposure to IFX from the Janssen global safety database. Only prospective reports 
Table 5 Congenital anomalies $(N=47$ events) reported in innovator infliximab prospective pregnancy reports

\begin{tabular}{|c|c|}
\hline Congenital anomaly & $\begin{array}{l}\text { Frequency } \\
\text { of events }\end{array}$ \\
\hline \multicolumn{2}{|l|}{ Live birth reports $(n=31)$} \\
\hline \multicolumn{2}{|l|}{ Major congenital anomalies } \\
\hline Atrial septal defect & $3^{\mathrm{b}}$ \\
\hline Gastroschisis & $3^{b}$ \\
\hline Hypospadias & $3^{b}$ \\
\hline Cardiac septal defect & 2 \\
\hline Cardiac perforation & 1 \\
\hline Coronary artery perforation & 1 \\
\hline Congenital cataract & $1^{\mathrm{b}}$ \\
\hline Down syndrome & 1 \\
\hline Vascular ring & 1 \\
\hline Bladder exstrophy & $1^{\mathrm{b}}$ \\
\hline Congenital bowing of long bones & 1 \\
\hline Congenital heart valve disorder & 1 \\
\hline Congenital intestinal malrotation & 1 \\
\hline Sacrococcygeal teratoma & $1^{\mathrm{b}}$ \\
\hline Persistent hyperplastic primary vitreous & $1^{b}$ \\
\hline Cryptorchidism & 1 \\
\hline Hypoplastic left heart syndrome & $1^{\mathrm{b}}$ \\
\hline Rectal-perineal fistula & 1 \\
\hline Renal agenesis (1 kidney) & 1 \\
\hline \multicolumn{2}{|l|}{ Minor congenital anomalies } \\
\hline Talipes & 2 \\
\hline Anteriorly placed anus & 1 \\
\hline Congenital hemangioma & $1^{\mathrm{b}}$ \\
\hline Chromosome 21 abnormality & 1 \\
\hline Cytogenetic analysis abnormal & 1 \\
\hline Laryngomalacia & 1 \\
\hline Left hand syndactyly & $1^{\mathrm{b}}$ \\
\hline Minor congenital metatarsus varus & 1 \\
\hline Polydactyly & $1^{\mathrm{b}}$ \\
\hline Congenital deformities of skull, face, and jaw & 1 \\
\hline Umbilical hernia & 1 \\
\hline Congenital anomaly NOS & 1 \\
\hline Congenital cardiovascular disorder NOS & $1^{\mathrm{b}}$ \\
\hline Teratogenicity & $1^{b}$ \\
\hline \multicolumn{2}{|l|}{ Abortions/intrauterine death reports $^{\mathrm{c}}(n=5)$} \\
\hline \multicolumn{2}{|l|}{ Major congenital anomalies } \\
\hline Down syndrome & $2^{b}$ \\
\hline Spinal dysplasia & $1^{\mathrm{b}}$ \\
\hline Congenital heart defect NOS & 1 \\
\hline \multicolumn{2}{|l|}{ Minor congenital anomalies } \\
\hline Unspecified congenital anomaly & $1^{\mathrm{b}}$ \\
\hline Abnormal fetus NOS & $1^{\mathrm{b}}$ \\
\hline
\end{tabular}

Table 5 (continued)

$N$ overall sample size, $n$ number of patients, NOS not otherwise specified

${ }^{\mathrm{a}} \mathrm{A}$ single report may note more than 1 congenital anomaly

${ }^{b}$ Mothers were receiving either methotrexate (atrial septal defect, congenital cataract, hypospadias, polydactyly, and congenital cardiovascular disorder NOS) or azathioprine/6-mercaptopurine (atrial septal defect, congenital hemangioma, sacrococcygeal teratoma, hypoplastic left heart syndrome, left hand syndactyly, teratogenicity, unspecified congenital anomaly, abnormal fetus NOS, bladder exstrophy, persistent hyperplastic primary vitreous, spinal dysplasia, Down syndrome, and gastroschisis) during pregnancy

${ }^{\mathrm{c}}$ This includes spontaneous, elective, or induced abortions; abortion unspecified; and abortion scheduled

were considered in the main analysis because retrospective reports are subject to reporting bias. Indeed, the data on IFX-exposed pregnancy reports extracted from the safety database confirm that the proportion of reports of adverse live birth outcomes and non-live births at least doubled when pregnancies were reported retrospectively compared with reports reported prospectively. Overall, the descriptive prospective data suggest that frequencies of adverse birth and infant outcomes among women exposed to IFX during pregnancy, irrespective of the trimester of exposure, were generally lower or similar to corresponding estimates from published studies on TNFi exposure in pregnant women (reviewed in Table 1) and in line with observed frequencies in the general population of pregnant women, irrespective of the trimester of exposure. For instance, in the IFX global safety database study, the rate of spontaneous abortions overall (12.1\%) was within range of the reported background risk of $10-20 \%$ in the general population [57]; the overall rate of preterm birth $(9.2 \%)$ was consistent with that of healthy US women with a rate of premature births of $10-11 \%$ [58]; and the overall combined rate of congenital anomalies of approximately $2.0 \%$ was comparable to the rate of major congenital anomalies estimated in the US general population $(\sim 3 \%)$ [14].

There were three reports of gastroschisis among infants born to IFX-exposed women (age range, 23-30 years) in the safety database ( $\sim 19$ per 10,000 live births), which is higher than that reported for the general population. However, several studies show that, recently, this birth defect has become more common, particularly among younger mothers and among women with a lower body mass index [51, 59-61]. Data for the general population originating from 14 states in the USA from 2006 to 2012 reported the prevalence of gastroschisis to be 16.1 per 10,000 births among younger mothers aged $<20$ years and 8.1 per 10,000 births among women 
aged 20-24 years, with overall prevalence being 4.9 per 10,000 births [61]. Potential risk factors in the woman who delivered two infants with gastroschisis were not reported; however, genetic susceptibility may have played a role [62]. The limited information regarding the two pregnant women experiencing a birth outcome of gastroschisis is insufficient to implicate an association with the use of IFX.

Prevalence of other congenital anomalies in our analysis, e.g., atrial septal defects $(0.16 \%$ vs. $0.13 \%)$ [63] and Down syndrome $(0.11 \%$ vs. $0.14 \%)$ [59, 64], was comparable to that in the general population. Women with IBD who were exposed to IFX during pregnancy reported the lowest rates of congenital anomalies among all disease indications evaluated (Crohn's disease: $1.9 \%$; ulcerative colitis: $<1.0 \%$ ). In contrast, women exposed to IFX who had rheumatologic indications had the highest prevalence of congenital anomalies (5.8\%). Overall, exposure to IFX during T1 or T3 did not seem to increase the risk of congenital anomalies compared with any other timing of exposure. These observations confirm other reports for TNFi therapy as a class, demonstrating no associated link between the use of TNFi during pregnancy and congenital malformations in the newborn [19-21, $23,25,65-68]$. The lack of any particular pattern in the types of congenital anomalies observed is also reassuring.

Innovator infliximab is often used in combination with methotrexate to treat rheumatologic disease. Methotrexate use has been associated with congenital anomalies [36, 37] and is contraindicated during pregnancy $[9,37]$. One study reported the risk of major congenital anomalies to be elevated in women exposed to methotrexate with autoimmune diseases (6.6\%) compared with women without autoimmune diseases (2.9\%) [69]. Although we did not assess the role of specific concomitant immunosuppressant use by indication, we observed a higher proportion of preterm births (13-18.8\%) and infant outcomes (8.7-12.5\%) in women reporting IFX use concomitantly with immunosuppressants during pregnancy than in the overall IFX-exposed population $(9.2 \%$ for preterm births and $7.2 \%$ for infant complications). No statistical testing for differences could be conducted because of the limitations of a spontaneous reporting database.

It is biologically plausible that exposure to TNFi during pregnancy can also affect the development of the infant's immune system, which could potentially increase the rate of AEs. One study of infants born to women treated throughout pregnancy with TNFi revealed changes in the infants' immune systems, including decreased T-regulatory cell frequency at birth and decreased response after mycobacterial challenge [70]. Another study showed that TNFi exposure during pregnancy can lead to neutropenia [71]. However, recent studies showed that exposure to biologics at any time or in $\mathrm{T} 3$ of pregnancy is not associated with an increased risk for serious or opportunistic infections in the first year of life $[15,72]$ and that observations of change in the immune system were not associated with clinical manifestations of serious infection in a small study of infants born to women exposed to TNFi throughout pregnancy [70]. Similarly, we have demonstrated in the current analysis that neonatal infections (including serious infections) were only reported in $\sim 1.0 \%$ of all IFX-exposed pregnancies. The risk of neonatal infections also did not appear to increase regardless of trimester of exposure, which further suggests that IFX exposure in utero does not increase the risk for infections.

Pregnancy and infant outcome data on other individual TNFi are scarce, but a few studies reported on pregnancy outcomes after exposure to certolizumab pegol. Among TNFi biologics, certolizumab pegol has been reported to be safe for treating pregnant women with chronic inflammatory diseases. Because this TNFi lacks an Fc portion, it is considered to have minimal to no placental transfer during T3 to infants [31] and, as such, might bear a lower risk for the infant. Interestingly, a recent publication reporting 1457 pregnancies exposed to $\mathrm{TNFi}$, mainly IFX or adalimumab, from clinical practice in France demonstrated that there is no increased risk in infections for infants born to mothers exposed to TNFi during pregnancy and that maintaining TNFi during T3 was also not associated with infections in the children [72]. Tumor necrosis factor- $\alpha$ inhibitor was associated with a higher risk of pregnancy complications (composite outcome) and maternal infections in this study [72], but similar observations were reported from a certolizumab pegol case series. Förger et al reported an increased susceptibility to maternal infection, in some cases leading to preterm birth, especially when certolizumab pegol was co-administered with low-dose prednisone [73]. Another study presented data on 528 pregnancies maternally exposed to certolizumab pegol with known outcomes [74]. Based on data extracted from a certolizumab pegol company safety database, these pregnancies resulted in similar proportions of live births, elective abortions, stillbirths, preterm births, and congenital anomalies, as observed in the IFX safety database (Table 3).

Several studies have suggested that other factors, such as disease activity and medications other than TNFi, confer incremental risk. While discontinuation of TNFi has been found to be safe in T2 in women with IBD who are in sustained remission [67], it has also been reported that patients who are not in remission may continue TNFi without any additional risks to the fetus [67]. In addition, it was observed in other studies that IBD disease activity and disease extent may augment the risk of adverse birth outcomes [25, 44, $75,76]$. For instance, women with pancolitis have been reported to have a significantly higher rate of spontaneous 
abortion $(23.0 \%$ vs. $0 \% ; p<0.04)$, preterm delivery $(36.0 \%$ vs. $5.0 \% ; p<0.02)$, and LBW (50.0\% vs. $14.0 \% ; p<0.02)$ than patients with limited ulcerative colitis [76]. Furthermore, more severe maternal rheumatoid arthritis has been associated with adverse birth outcomes (e.g., preterm birth, SGA, and cesarean birth) and a 58\% increased risk of preterm delivery for each unit increase in the Health Assessment Questionnaire-Disability Index, an indicator of disease severity [77]. Additionally, in mothers with psoriasis, severe disease has been associated with a significant increase in risk of delivering a LBW infant compared with mothers without psoriasis, whereas no increased risks have been associated with mild psoriasis. In contrast, preterm birth, SGA, cesarean birth, and preeclampsia/eclampsia have not been associated with severe psoriasis [78]. Based on an overall review of clinical evidence across all indications, women with active or flaring disease during pregnancy are at a higher risk for adverse birth outcomes, irrespective of exposure to biologic therapy.

Because most of the data sources used in this analysis lacked detailed information on peri-pregnancy severity of disease, exposure to concomitant systemic immunosuppressant medication could be considered as a surrogate for disease activity. Thus, continued use of concomitant conventional immunosuppressant, such as corticosteroids, thiopurines, and even methotrexate in combination with IFX, can also be considered a marker of more severe disease. In our current analysis of the Janssen safety database, nearly onethird of women exposed to IFX during pregnancy reported to have received combination therapy, supporting the hypothesis that multiple factors in addition to exposure to IFX might determine birth outcome rates.

Overall strengths of this investigation include its large sample size collected over a 20 -year period in a global safety database and containing information on pregnancies worldwide that were exposed to IFX between 1998 and 2018. The data source also has limitations. A substantial proportion of data entries is derived from voluntary reports by or on behalf of the patient with a large amount of missing information, both of which can limit methodologically appropriate statistical comparisons. There are important limitations to consider when using spontaneously reported AE information, including report quality, which determines the ability to assess and analyze the safety issues. The initial report might be limited to the absolute minimum information constituting an $\mathrm{AE}$, which includes a reporter, a patient, an adverse reaction, and a medication exposure. For the reporting of exposed pregnancies, Janssen sends out pregnancy follow-up forms to collect more complete information on the pregnancy outcomes as well as other information associated with the pregnancy such as concomitant medications and past medical history. In the event that the pregnancy follow-up form is returned to the company, all fields are not always completed, which may mean there is nothing to report or there is missing information that was not provided. For instance, while exposure to concomitant medications is reported for some reports, the lack of a report of concomitant medications does not necessarily mean that the patient did not take concomitant medications, it may mean that the information is not reported.

Spontaneously reported data also have other caveats described in detail elsewhere [79]. Briefly, spontaneous reporting of AEs may involve underreporting of pregnancies and outcomes to the company by the patients and/or clinicians, may be highly variable, which may skew the data towards unfavorable outcomes (i.e., clinicians may be less likely to report non-serious AEs or AEs frequently observed in the general population), and important information regarding concomitant medications and relevant medical history may not always be captured.

Other limitations of the study included a lack of a longterm follow-up of infants born to women who were exposed to IFX during pregnancy as well as limited information being available to assess the effect of lactation on adverse outcomes. However, even with these limitations, it is noted that very few studies describing birth outcomes in women exposed to IFX have been published. Therefore, the current study provides meaningful information for the treatment of women of childbearing age with immune-mediated inflammatory diseases.

\section{Conclusions}

This study represents the largest study to date investigating the outcomes of exposure to IFX during pregnancy using data over a 20 -year period from a global safety database. Based on this analysis, the prevalence of adverse pregnancy, birth, and infant outcomes is consistent with that of the general population and with published data on TNFi therapies. Our findings provide a detailed descriptive summary of maternal exposure to IFX and adverse infant clinical outcomes, such as congenital anomalies and infections, which can aid clinicians and women of childbearing age in their treatment plans and decision making.

Acknowledgements The authors acknowledge Debra Cipriani, MD, of Janssen Research and Development for assisting with congenital anomaly data interpretation. The authors also acknowledge Chastity Bradley, PhD, of Synchrogenix, A Certara Company for medical writing assistance.

Author Contributions All authors were involved in the study design, conduct of the study, collection of the data, data interpretation, and writing/editing of the manuscript. All authors have approved the final draft of the manuscript. 


\section{Compliance with Ethical Standards}

Funding This study was supported by Janssen Pharmaceutical Companies of Johnson \& Johnson. Janssen was involved in all aspects of the study (design and conduct of the study; collection, management, analysis, and interpretation of data; preparation, review, and approval of the manuscript; and decision to submit the manuscript for publication).

Conflict of interest Anja Geldhof, Jennifer Slater, Michael Clark, Urmila Chandran, and Danielle Coppola are employees of Janssen Research \& Development or Janssen Biologics Division and may own company stock/stock options.

Data Sharing The datasets generated during and/or analyzed during the current analysis are not publicly available because access to pharmacovigilance data must always be considered in respect to European Union laws, which protect the patient's rights to personal privacy. However, upon reasonable request, the data may be made available by contacting the corresponding author.

Ethics Approval This observational analysis was based on pregnancy safety data extracted from a global safety database. Clinical trial registration and ethical approval were not required for this analysis. This article also does not contain any data from animals performed by any of the authors.

Consent to Participate Cumulative pregnancy safety data from a global safety surveillance database were summarized in this observational analysis. No identifying patient information was reported; therefore, no additional informed consent was required.

Open Access This article is distributed under the terms of the Creative Commons Attribution-NonCommercial 4.0 International License (http://creativecommons.org/licenses/by-nc/4.0/), which permits any noncommercial use, distribution, and reproduction in any medium, provided you give appropriate credit to the original author(s) and the source, provide a link to the Creative Commons license, and indicate if changes were made.

\section{References}

1. Fonager K, Sørensen HT, Olsen J, et al. Pregnancy outcome for women with Crohn's disease: a follow-up study based on linkage between national registries. Am J Gastroenterol. 1998;93:2426-30.

2. Baiocco PJ, Korelitz BI. The influence of inflammatory bowel disease and its treatment on pregnancy and fetal outcome. J Clin Gastroenterol. 1984;6:211-6.

3. Lin HC, Chen SF, Lin HC, et al. Increased risk of adverse pregnancy outcomes in women with rheumatoid arthritis: a nationwide population-based study. Ann Rheum Dis. 2010;69:715-7.

4. Bobotsis R, Gulliver WP, Monaghan K, et al. Psoriasis and adverse pregnancy outcomes: a systematic review of observational studies. Br J Dermatol. 2016;175:464-72.

5. Reddy D, Murphy SJ, Kane SV, et al. Relapses of inflammatory bowel disease during pregnancy: in-hospital management and birth outcomes. Am J Gastroenterol. 2008;103:1203-9.

6. Khosla R, Willoughby CP, Jewell DP. Crohn's disease and pregnancy. Gut. 1984;25:52-6.

7. Mayberry JF, Weterman IT. European survey of fertility and pregnancy in women with Crohn's disease: a case control study by European Collaborative Group. Gut. 1986;27:821-5.
8. Mogadam M, Korelitz BI, Ahmed SW, et al. The course of inflammatory bowel disease during pregnancy and postpartum. Am J Gastroenterol. 1981;75:265-9.

9. Vinet E, Kuriya B, Pineau CA, Clarke AE, Bernatsky S. Induced abortions in women with rheumatoid arthritis receiving methotrexate. Arthritis Care Res (Hoboken). 2013;65(8):1365-9.

10. Given JE, Loane M, Luteijn JM, et al. EUROmediCAT signal detection: an evaluation of selected congenital anomaly-medication associations. Br J Clin Pharmacol. 2016;82:1094-109.

11. Simister NE. Placental transport of immunoglobulin G. Vaccine. 2003;21:3365-9.

12. Arsenescu R, Arsenescu V, de Villiers WJ. TNF-alpha and the development of the neonatal immune system: implications for inhibitor use in pregnancy. Am J Gastroenterol. 2011;106:559-62.

13. The American College of Obstetricians and Gynecologists. Early pregnancy loss: miscarriage and molar pregnancy. Washington, DC. FAQ090, August 2015.

14. Centers for Disease Control and Prevention (CDC). Update on overall prevalence of major birth defects: Atlanta, Georgia, 19782005. MMWR Morb Mortal Wkly Rep. 2008;57:1-5.

15. Chambers CJ, Johnson DL, Luo Y, et al. Serious or opportunistic infections in infants born to women with rheumatoid arthritis treated with a biologic medication [abstract]. Arthritis Rheum. 2017;69 (Suppl. 10). https://acrabstracts.org/abstract/seriousor-opportunistic-infections-in-infants-born-to-pregnant-women -with-rheumatoid-arthritis-and-treated-with-a-biologic-medic ation/. Accessed 26 Feb 2019.

16. Burmester GR, Landewé R, Genovese MC, et al. Adalimumab long-term safety: infections, vaccination response and pregnancy outcomes in patients with rheumatoid arthritis. Ann Rheum Dis. 2017;76(2):414-7.

17. Carman WJ, Accortt NA, Anthony MS, et al. Pregnancy and infant outcomes including major congenital malformations among women with chronic inflammatory arthritis or psoriasis, with and without etanercept use. Pharmacoepidemiol Drug Saf. 2017;26:1109-18.

18. Casanova MJ, Chaparro M, Domenech E, et al. Safety of thiopurines and anti-TNF- $\alpha$ drugs during pregnancy in patients with inflammatory bowel disease. Am J Gastroenterol. 2013;108:433-40.

19. Cooper WO, Cheetham TC, Li DK, et al. Adverse fetal outcomes associated with immunosuppressive medications for chronic immune mediated diseases in pregnancy. Arthritis Rheumatol. 2014;66:444-50.

20. Diav-Citrin O, Otcheretianski-Volodarsky A, Shechtman S, et al. Pregnancy outcome following gestational exposure to TNF$\alpha$-inhibitors: a prospective, comparative, observational study. Reprod Toxicol. 2014;43:78-84.

21. Komoto S, Motoya S, Nishiwaki Y, et al. Pregnancy outcome in women with inflammatory bowel disease treated with anti-tumor necrosis factor and/or thiopurine therapy: a multicenter study from Japan. Intest Res. 2016;14:139-45.

22. Schnitzler F, Fidder H, Ferrante M, et al. Outcome of pregnancy in women with inflammatory bowel disease treated with antitumor necrosis factor therapy. Inflamm Bowel Dis. 2011;17:1846-54.

23. Seirafi M, de Vroey B, Amiot A, et al. Factors associated with pregnancy outcome in anti-TNF treated women with inflammatory bowel disease. Aliment Pharmacol Ther. 2014;40:363-73.

24. Kammerlander H, Nielsen J, Knudsen T, et al. Anti-TNF- $\alpha$ use during the third trimester of pregnancy in women with moderatesevere inflammatory bowel disease and the risk of preterm birth and low birth weight. Inflamm Bowel Dis. 2017;23:1916-23.

25. Bröms G, Granath F, Ekbom A, et al. Low risk of birth defects for infants whose mothers are treated with anti-tumor necrosis factor agents during pregnancy. Clin Gastroenterol Hepatol. 2016;14(234-41):e1-5. 
26. Chaparro M, Verreth A, Lobaton T, et al. Long-term safety of in utero exposure to anti-TNF alpha drugs for the treatment of inflammatory bowel disease: results from the multicenter European TEDDY study. Am J Gastroenterol. 2018;113:396-403.

27. Lichtenstein GR, Feagan BG, Mahadevan U, et al. Pregnancy outcomes reported during the 13-year TREAT Registry: a descriptive report. Am J Gastroenterol. 2018;113:1678-88.

28. Vinet É, De Moura C, Pineau CA, et al. Serious infections in rheumatoid arthritis offspring exposed to tumor necrosis factor inhibitors: a cohort study. Arthritis Rheumatol. 2018;70:1565-71.

29. Komaki F, Komaki Y, Micic D, et al. Outcome of pregnancy and neonatal complications with anti-tumor necrosis factor- $\alpha$ use in females with immune mediated diseases; a systematic review and meta-analysis. J Autoimmun. 2017;76:38-52.

30. Mirdamadi K, Salinas T, Vali R, et al. Meta-analysis of pregnancy outcomes after exposure to TNF-alpha inhibitors for the treatment of arthritic diseases: a meta-analysis of observational studies. J Popul Ther Clin Pharmacol. 2018;25:e53-6.

31. Mariette X, Förger F, Abraham B, et al. Lack of placental transfer of certolizumab pegol during pregnancy: results from CRIB, a prospective, postmarketing, pharmacokinetic study. Ann Rheum Dis. 2018;77:228-33.

32. Bjørn AM, Ehrenstein V, Nohr EA, et al. Use of inhaled and oral corticosteroids in pregnancy and the risk of malformations or miscarriage. Basic Clin Pharmacol Toxicol. 2015;116:308-14.

33. Sanya R, Al Naggar E, Gasim M, et al. Use or overuse of antenatal corticosteroids for suspected preterm birth. J Matern Fetal Neonatal Med. 2014;27:1454-6.

34. Park-Wyllie L, Mazzotta P, Pastuszak A, et al. Birth defects after maternal exposure to corticosteroids: prospective cohort study and meta-analysis of epidemiological studies. Teratology. 2000;62:385-92.

35. Plauborg AV, Hansen AV, Garne E. Use of azathioprine and corticosteroids during pregnancy and birth outcome in women diagnosed with inflammatory bowel disease. Birth Defects Res A Clin Mol Teratol. 2016;106:494-9.

36. Dawson AL, Riehle-Colarusso T, Reefhuis J, Arena JF, National Birth Defects Prevention Study. Maternal exposure to methotrexate and birth defects: a population-based study. Am J Med Genet A. 2014;164:2212-6.

37. Methotrexate sodium for injection. Florence (KY): Xanodyne Pharmacal, Inc; 2003.

38. Palmsten K, Rolland M, Hebert MF, et al. Patterns of prednisone use during pregnancy in women with rheumatoid arthritis: daily and cumulative dose. Pharmacoepidemiol Drug Saf. 2018;27:430-8.

39. Wallenius M, Lie E, Daltveit AK, et al. No excess risks in offspring with paternal preconception exposure to disease-modifying antirheumatic drugs. Arthritis Rheumatol. 2015;67:296-301.

40. Micu MC, Bojinca V, Mihai M, et al. Pregnancy outcome in couples with males exposed to longterm anti-TNF alpha blocker therapies. Ann Rheum. 2016;75(Suppl. 2):802.

41. Micu MC, Ostensen M, Bojinca V, et al. Pregnancy outcomes in couples with males exposed to long term anti-TNF alpha blocker therapies: a prospective study. J Rheumatol. 2019;46(9):1084-8. https://doi.org/10.3899/jrheum.180588.

42. Mouyis M, Flint JD, Giles IP. Safety of anti-rheumatic drugs in men trying to conceive: a systematic review and analysis of published evidence. Semin Arthritis Rheum. 2019;48:911-20.

43. Larsen MD, Friedman S, Magnussen B, et al. Birth outcomes in children fathered by men treated with anti-TNF- $\alpha$ agents before conception. Am J Gastroenterol. 2016;111:1608-13.

44. Pregnancy due date and gestational age calculator. 2016. http://www. perinatology.com/calculators/Due-Date.htm. Accessed 21 Sept 2017.

45. International Conference on Harmonisation of Technical Requirements for Registration of Pharmaceuticals for Human Use. ICH
Harmonised Tripartite Guideline. Clinical safety data management: definitions and standards for expedited reporting E2A, 1994.

46. Rules governing medicinal products in the European Union. Guidelines on pharmacovigilance for medicinal products for human use. Volume 9A, 2008.

47. Centers for Disease Control and Prevention. Congenital anomalies: definitions. US Department of Health \& Human Services. Washington, DC, 2018.

48. Jones J, Borgaonkar M, Siffledeen J, et al. Bioadvance patient support program survey: positive perception of intravenous infusions of infliximab. Manag Care. 2017;26:41-8.

49. van der Horst HJR, de Wall LL. Hypospadias, all there is to know. Eur J Pediatr. 2017;176:435-41.

50. Reller MD, Strickland MJ, Riehle-Colarusso T, et al. Prevalence of congenital heart defects in metropolitan Atlanta, 1998-2005. J Pediatr. 2008;153:807-13.

51. Parker SE, Mai CT, Canfield MA, et al. Updated national birth prevalence estimates for selected birth defects in the United States, 2004-2006. Birth Defects Res A Clin Mol Teratol. 2010;88:1008-16.

52. Clowse ME. The use of anti-TNF $\alpha$ medications for rheumatologic disease in pregnancy. Int J Womens Health. 2010;2:199-209.

53. Carter JD, Ladhani A, Ricca LR, et al. A safety assessment of tumor necrosis factor antagonists during pregnancy: a review of the Food and Drug Administration database. J Rheumatol. 2009;36:635-41.

54. Koren G, Inoue M. Do tumor necrosis factor inhibitors cause malformations in humans? J Rheumatol. 2009;36:465-6.

55. Infliximab periodic benefit risk evaluation report/periodic safety update report. Horsham (PA): Janssen Research \& Development, LLC; 2018.

56. Katz JA, Antoni C, Keenan GF, et al. Outcome of pregnancy in women receiving infliximab for the treatment of Crohn's disease and rheumatoid arthritis. Am J Gastroenterol. 2004;99:2385-92.

57. Borrell A, Stergiotou I. Miscarriage in contemporary maternalfetal medicine: targeting clinical dilemmas. Ultrasound Obstet Gynecol. 2013;42:491-7.

58. Hamilton BE, Martin JA, Osterman MJ, et al. Births: final data for 2014. Natl Vital Stat Rep. 2015;64:1-64.

59. Kirby RS. The prevalence of selected major birth defects in the United States. Semin Perinatol. 2017;41:338-44.

60. Kirby RS, Marshall J, Tanner JP, et al. Prevalence and correlates of gastroschisis in 15 states, 1995 to 2005. Obstet Gynecol. 2013;122:275-81.

61. Centers for Disease Control and Prevention (CDC). Increasing prevalence of gastroschisis: 14 states, 1995-2012. MMWR Morb Mortal Wkly Rep. 2016;65:23-6.

62. Padula AM, Yang W, Schultz K, et al. Gene variants as risk factors for gastrochisis. Am J Med Genet Part A. 2016;170A:2788-802.

63. Centers for Disease Control and Prevention (CDC). Atrial septal defects. https://rarediseases.org/rare-diseases/atrial-septal-defec ts/. Accessed 06 Dec 2018

64. Centers for Disease Control and Prevention (CDC). Occurrence of Down syndrome in the United States. 2017. https://www.cdc. gov/ncbddd/birthdefects/downsyndrome/data.html. Accessed 06 Dec 2018

65. Narula N, Al-Dabbagh R, Dhillon A, et al. Anti-TNF $\alpha$ therapies are safe during pregnancy in women with inflammatory bowel disease: a systematic review and meta-analysis. Inflamm Bowel Dis. 2014;20:1862-9.

66. Shihab Z, Yeomans ND, De Cruz P. Anti-tumour necrosis factor $\alpha$ therapies and inflammatory bowel disease pregnancy outcomes: a meta-analysis. J Crohns Colitis. 2016;10:979-88.

67. de Lima A, Zelinkova Z, van der Ent C, et al. Tailored anti-TNF therapy during pregnancy in patients with IBD: maternal and fetal safety. Gut. 2016;65:1261-8. 
68. Weber-Schoendorfer C, Oppermann M, Wacker E, et al. Pregnancy outcome after TNF- $\alpha$ inhibitor therapy during the first trimester: a prospective multicentre cohort study. Br J Clin Pharmacol. 2015;80:727-39.

69. Weber-Schoendorfer C, Chambers C, Wacker E, et al. Pregnancy outcome after methotrexate treatment for rheumatic disease prior to or during early pregnancy: a prospective multicenter cohort study. Arthritis Rheumatol. 2014;66:1101-10.

70. Esteve-Solé A, Deya-Martinez A, Teixido I, et al. Immunological changes in blood of newborns exposed to anti-TNF- $\alpha$ during pregnancy. Front Immunol. 2017;8:1123.

71. Guiddir T, Frémond ML, Triki TB, et al. Anti-TNF- $\alpha$ therapy may cause neonatal neutropenia. Pediatrics. 2014;134:e1189-93.

72. Luu M, Benzenine E, Doret M, et al. Continuous anti-TNF $\alpha$ use throughout pregnancy: possible complications for the mother but not for the fetus: a retrospective cohort on the French National Health Insurance database (EVASION). Am J Gastroenterol. 2018;113:1669-77.

73. Förger F, Zbinden A, Villiger PM. Certolizumab treatment during late pregnancy in patients with rheumatic diseases: low drug levels in cord blood but possible risk for maternal infections: a case series of 13 patients. Jt Bone Spine. 2016;83:341-3.
74. Clowse MEB, Scheuerle AE, Chambers C, et al. Pregnancy outcomes after exposure to certolizumab pegol: updated results from a pharmacovigilance safety database. Arthritis Rheumatol. 2018;70:1399-407.

75. Mahadevan U. Fertility and pregnancy in the patient with inflammatory bowel disease. Gut. 2006;55:1198-206.

76. Puri A, Bharadwaj V, Sachdeva S. Extent of disease is a major outcome predictor in patients with ulcerative colitis and pregnancy. Indian J Gastroenterol. 2015;34:108-11.

77. Bharti B, Lee SJ, Lindsay SP, et al. Disease severity and pregnancy outcomes in women with rheumatoid arthritis: results from the organization of teratology information specialists autoimmune diseases in pregnancy project. J Rheumatol. 2015;42:1376-82.

78. Yang YW, Chen CS, Chen YH, et al. Psoriasis and pregnancy outcomes: a nationwide population-based study. J Am Acad Dermatol. 2011;64:71-7.

79. Brunner E, Falk DM, Jones M, et al. Olanzapine in pregnancy and breastfeeding: a review of data from global safety surveillance. BMC Pharmacol Toxicol. 2013;14:38. 